\title{
La trama del archivo. Reflexiones desde la antropología y la historia. Entrevista a Sofía Tiscornia y a Lila Caimari
}

\section{María Eva Muzzopappa}

emuzzopappa@unrn.edu.ar

Instituto de Investigaciones en Diversidad y Procesos de Cambio (IIDyPCa), Universidad Nacional de Río Negro (UNRN) / CONICET, Argentina

\section{Mariana Nazar}

mariananazar@gmail.com

Dirección de Gestión del Conocimiento,

Investigaciones y Publicaciones del Instituto Nacional de la Administración Pública (INAP), Escuela de

Política y Gobierno, Universidad Nacional de San

Martín (EpyG-UNSAM) / Asociación de Archivistas

en la Función Pública Argentina (AFPA), Argentina

Cita sugerida: Muzzopappa, M. E. y Nazar, M. (2021). La trama del archivo. Reflexiones desde la antropología y la historia.

Entrevista a Sofía Tiscornia y a Lila Caimari. Aletheia, 11(22), e089. https://doi.org/10.24215/18533701e089

\section{INTRODUCCIÓN}

Las protagonistas de esta entrevista son una antropóloga, Sofía Tiscornia, y una historiadora, Lila Caimari. Ambas cuentan con una sólida y extensa trayectoria, que puede rastrearse a partir de sus producciones académicas. Sin embargo, la invitación para hacerles esta entrevista no se redujo atendiendo meramente a estos logros. Por el contrario, fue pensada debido al impacto que sus propuestas han tenido en buena parte de las/os autoras/es del dossier de este número de Aletheia. Tanto Lila Caimari como Sofía Tiscornia han logrado establecer líneas fundamentales de trabajo e investigación en sus respectivas disciplinas, con una fuerte interpelación a los debates públicos. Lejos de delimitar las discusiones a la academia, los equipos que dirigen han impactado fuertemente en la agenda pública sobre temas y nociones tales como las de derechos humanos, policía, delito y criminalidad, entre otros. En esos efectos, asimismo, se dimensiona el lugar que han ocupado en tanto maestras. Tal como es proclamado por el campo de 
estudios de la perspectiva de género, consideramos necesario explicitar estas genealogías femeninas para visibilizar la densidad y potencialidad de este tipo de experiencias (Balbuena, 2019) y así, honrarlas.

Lila Caimari, en su rol de historiadora, se ha dedicado a analizar diversas dimensiones de la vida social y cultural de la Argentina del Siglo XX, en particular, a partir de la cuestión criminal. Para abordar estas temáticas se ha adentrado profundamente en una diversidad de archivos poco trabajados, tanto en relación con sus limitadas condiciones de puesta al acceso como a su escaso uso por parte de la investigación. En esa línea, la creación y dirección del grupo de estudios Crimen y Sociedad ${ }^{1}$ destinado a analizar el delito, la policía, la justicia y la prisión en perspectiva histórica, constituyó un fructífero campo de estudios en la Argentina. En el mismo, el lugar del archivo ocupa desde sus orígenes un lugar de reflexión tanto como potencialidad para la construcción de saberes como de manifestación del poder. Ese conocimiento y ese habitar los archivos como historiadora sociocultural, pero también como tallerista acompañando el desarrollo de investigaciones de posgrado y como directora de tesis la llevaron a plasmar sus reflexiones en una variedad de escritos, conferencias y otras intervenciones públicas en torno a lo que describe como una de las estaciones habitualmente consideradas menos brillantes de la investigación histórica (Caimari, 2017).

Por su parte, Sofía Tiscornia ${ }^{2}$ ha logrado hacer del trabajo con documentos en la antropología una seña de identidad. Su introducción al mundo de los registros escritos configuró una forma de investigación en la cual se entrelazan las reflexiones académicas y las urgencias de la militancia; las demandas de los organismos de derechos humanos fueron traducidas en la necesidad de un estudio y un análisis de las burocracias estatales. Para ello, su perspectiva como antropóloga atendió específicamente a comprender el lenguaje jurídico y policial y sus reglas, dirigiendo así la mirada sobre esta particular creación de registros que implica la "vida" de toda organización burocrática. Esas particulares discusiones e intervenciones forman parte de lo que es el Equipo de Antropología Política y Jurídica, ${ }^{3}$ donde las investigaciones privilegian el análisis de los dispositivos burocráticos y las rutinas de los funcionarios, así como la malla de relaciones sociales y políticas en las cuales la violencia estatal puede desplegarse. Las etnografías se detienen, entonces, en el funcionamiento cotidiano de estas oficinas en las cuales los registros escritos -expedientes, formularios, órdenes del día, entre otros- se convierten en una vía de indagación sobre la performatividad de la "palabra" del estado.

Esta mirada metodológica y analítica permite reconstruir casos y situaciones burocráticas no como meros "estados de situación", sino como un punto en un continuo de mundos cotidianos en los cuales transitan y constituyen cotidianamente sus agentes, se dirimen y disputan marcos y límites, y donde los registros son una forma de entrada para dar cuenta de ese campo que se recrea, se tensiona, se dirime en una larga duración.

La entrevista fue pensada originalmente a dos voces, con el acuerdo de un punteo de preguntas -guía para el desarrollo de la conversación- que se incluyen en la transcripción. Los tiempos y las dificultades pandémicas hicieron que lo que originalmente fuera pensado para suceder en un encuentro se dividiera finalmente en dos instancias: una de entrevista sincrónica, con Lila Caimari, y una de respuestas escritas, de Sofía Tiscornia; ambas se transcriben en la Primera parte: reflexiones antropológicas e historiográficas sobre los archivos y sus usos. Esta versión combina sus testimonios, con la aprobación y revisión de ambas, en una simulación de entrevista conjunta. La diferencia de situaciones de entrevista implicó una diferencia sustancial en la extensión de las respuestas, mucho más amplia en el registro de la conversación, y que además permite incluir algunas otras preguntas. La riqueza, actualidad e importancia de lo surgido en esta instancia nos llevó a incluir una segunda parte, titulada Luces y sombras del acceso a los archivos en tiempos de humanidades digitales, en la cual se encuentra solo la voz de Lila Caimari. 


\section{Primera PARTE: REFLEXIONES ANTROPOLÓgICAS E HISTORIOGRÁfiCAS SOBRE LOS ARCHIVOS} Y SUS USOS

\section{Entrevistadoras: ¿ cómo fueron sus aproximaciones al trabajo con archivos? ¿cuáles eran los objetivos de sus respectivas búsquedas? ¿qué esperaban encontrar y qué fue lo que efectivamente encontraron?}

Sofía Tiscornia: Una primera cuestión, para marcar el tono de mi intervención en esta conversación, es que las aproximaciones -porque no han sido más que aproximaciones- que he tenido a archivos en algunas de las investigaciones y trabajos realizados, han sido parte de eso que les antropologues llamamos genéricamente, trabajo de campo. Quiero decir, he interrogado a los archivos, he buscado en ellos, sin la rigurosidad que la historia ha enseñado a quienes la hacen. Para decirlo de alguna forma, los archivos han sido casi un actor más, un actor muchas veces insoslayable, de las búsquedas que el tema de la investigación exigía. Y por eso he pensado más de una vez que los archivos -judiciales, policiales, de organismos de derechos humanos- han sido siempre para mí archivos vivos, en movimiento y en escenas.

Sin duda esta aproximación peculiar responde a que he trabajado sobre problemas contemporáneos, quiero decir, que están ocurriendo pero que, al mismo tiempo, para su comprensión, exigen entender su anclaje en la historia y en la memoria social. Los tribunales, el derecho, las policías, bien lo sabemos, son burocracias complejas y amantes a su modo, de su prosapia histórica y de cómo la producen y en ella fincan buena parte de su legitimación. Por eso, la búsqueda en sus archivos no ha sido solo búsquedas para la construcción de los datos, para encontrar las evidencias, para probar genealogías, sino también para comprender cómo funcionan, cómo piensan, cómo trabajan, cuáles son las rutinas de esas burocracias. Y cuán heterogéneas son. Y cuán celosas de sus secretos, de la información que atesoran, pero también de su indolencia.

He buscado muchas cosas en diferentes archivos: datos cuantitativos en la Dirección Nacional de Reincidencia en los tempranos 90; expedientes perdidos en archivos de juzgados y en la Corte Suprema de Justicia; pero debo decir que la búsqueda más tenaz fue provocada justamente por las inmensas dificultades que la dispersión, el maltrato de los materiales, el oscuro lenguaje jurídico, y las trampas de las memorias políticas provocan y fue cuando me propuse investigar las detenciones por edicto de policía a un grupo de señoras de la oligarquía porteña que protestaban en la calle Florida contra la reforma de la constitución de 1948 (Tiscornia, 2004). A decir verdad, no me había propuesto ahondar en la historia, y menos del peronismo sin ser una experta, pero necesitaba saber por qué los abogados usaban para discutir la aplicación de los edictos de policía un fallo en particular, quería averiguar qué conflicto había motivado ese fallo judicial. No voy a repetir la historia que ya he escrito, pero sí me parece que ahí queda bastante claro ese uso particular de los archivos que a veces hacemos les antropologues. Y también las particularidades que los usos diarios e instrumentales de la documentación judicial imprimen a los archivos. Por eso digo, me gusta llamarlos archivos vivos.

Y también a algunos, como al archivo del CELS -que incluye dictadura y democracia -casi diría que lo he visto nacer, y he contribuido alguna vez a alimentarlo, crecer y luego profesionalizarse.

Lila Caimari: Yo pensé estas reflexiones en torno a la experiencia de hace años y pensaba todo el camino recorrido desde entonces y me parece interesante reflexionar sobre eso. En mi caso, fueron dos archivos en particular en los que tuve experiencias más intensas. Uno era el archivo del Instituto de Criminología del Servicio Penitenciario Federal, y el otro era la biblioteca Romay, digamos, el Centro de Estudios Históricos Romay de la Policía Federal, que en aquellos años estaban uno a la vuelta del otro, ubicados espacialmente muy cerquita uno del otro por pura casualidad. Fue tan intensa la relación con esos archivos en mi caso que yo diría que mi camino hacía el giro archivístico transcurrió ahí. Todo el camino de aprendizaje, de reflexión sobre el archivo más en general, transcurrió en contacto con esos archivos que eran archivos de enorme interés y muy desconocidos por nosotros. ¿Qué era lo que me había sorprendido? Yo llegaba con expectativas muy ingenuas, sin mucha idea de qué era lo me iba a encontrar. A partir de ahí, la curva de aprendizaje fue muy empinada en los años siguientes y ahora está en una nueva meseta. Pero durante esos primeros años hubo una 
intensidad del descubrimiento que nos marcó mucho a varios de los que estaban en nuestro equipo, al punto que nos llevó a escribir y reflexionar sobre temas vinculados a la policía, sobre temas tales como la escritura burocrática, construcciones de archivo, etc. Eso fue un primer desvío, o un primer efecto.

Lo primero que me sorprendió es que papeles tan valiosos, con tanta potencia historiográfica, estuvieran tirados en un rincón y que fueran tan poco conocidos. Después, algo que fue un aprendizaje en mi caso, era que se trataba de burocracias. Una llegaba con una idea un poco mítica sobre qué era lo que iba a encontrar en ese archivo, secretos, revelaciones ocultas; y encontraba, en buena medida, que era producto de una burocracia, y entonces, había que ponerse a estudiar ese sistema de producción y de circulación. Y que eso era una parte importante de lo que teníamos por delante. Resultaba a la vez un hallazgo un poco desencantador y, por otra parte, repleto de desafíos hacia adelante, que establecían ciertos caminos de aprendizaje, de evaluación de posibilidades de lo que se podía hacer y lo que no se podía hacer. Un descubrimiento también con relación al contexto en el que transcurría este descubrimiento, sentados en las oficinas junto a los productores de papeles burocráticos del presente. Es decir, los historiadores solemos ir al archivo y, en general, ese archivo está aislado de las instituciones productoras del pasado. Algo que inyectó mucha intensidad a la experiencia era que a la vez que recorríamos esas series, escuchábamos hablar, interactuar y veíamos funcionar a oficinas que en el presente estaban produciendo documentos que en algunos casos eran comparables o que tenían, digamos, continuidades. Eso le agregó, si se quiere, una dimensión etnográfica al trabajo historiográfico que, en general, no tiene esa dimensión. Y eso fue muy importante también para pensar los caminos y las lógicas que subyacían a estos corpus.

Otro hallazgo fue la variedad enorme de documentos distintos que había, sobre todo, en el archivo de la biblioteca de la Policía Federal. Es distinto a la prisión, el sistema penitenciario produce archivos que son más homogéneos, aunque también por supuesto hay cosas bien distintas. En el caso de la policía encontré un abanico inesperado de producción escrita que iba desde memorias y órdenes del día, hasta revistas con colocaciones distintas -algunas para adentro de la institución, otras para afuera- había una variedad enorme y, por lo tanto, un potencial de cosas diferentes que podían hacerse con esos materiales. Entonces había que elegir qué camino tomar, qué caminos dejar de lado, o por lo menos, dejar en suspenso, o tratar de delegar en manos de otros miembros del equipo, porque esa variedad también implicaba que los potenciales eran diversos y que los caminos de trabajo tenían por fuerza que ser distintos. Entonces, ahí había algo que yo no había previsto y eso también explica el tiempo que llevó conocer esos archivos, mapearlos y comenzar a pensar cómo trabajarlos, qué se podía hacer, qué no se podía hacer, cuáles eran las posibilidades y cuáles eran también las trampas, los desafíos y los peligros metodológicos que se abrían que quizás distintos de los que esperaba.

Otra cosa que me sorprendió también fue lo explícito de tantos documentos que daban detalles y brindaban información muy pormenorizada sobre muchísimas instancias de intervención policial en la sociedad. Intervención represiva, sobre todo, orden político, orden social, espionaje, digamos, todas esas cosas que yo creía iban a ser producto de búsquedas clandestinas estaban ahí. Había ya una base muy explícita y frondosa, con lo cual volvía sobre mi perplejidad de que esto no se hubiera investigado antes. Había habido antes gente que trabajó sobre estas cosas, pero me parecía que eran como islas, un par de colegas que habían trabajado antes que nosotros. Pero el potencial de intervención de estos materiales en la historia argentina concebido en sentido amplio, no solamente en la historia de la policía- era algo por descubrir. Y esta es otra cuestión que también fue un hallazgo, algo que sigue estando pendiente. Y es el potencial de estos archivos para intervenir no solamente en las discusiones específicas de historia de las policías o historia de las fuerzas de seguridad o historia del delito incluso, sino también para intervenir en la historia grande del pasado de la sociedad argentina y de las instituciones argentinas. De entrar a diálogos que no eran diálogos de nicho, sino que se podía salir a dialogar y a intervenir en los cuadros que teníamos ya consensuados sobre cómo era el Estado argentino, cómo eran las instituciones, cómo era la sociedad, etc. Eran materiales con alto potencial historiográfico a muchos niveles. Y era cuestión entonces de salir a correr a la voz de que esto merecía la pena. Hemos sido hasta ahora más exitosos dentro de la primera avenida, es decir, en alentar el 
interés dentro del campo de estudios de la cuestión criminal o de las fuerzas de seguridad, y menos en atraer investigadores sociales al archivo de la policía o al archivo penitenciario. El archivo penitenciario guarda muchísima información sobre condiciones de vida de poblaciones que por lo general dejan poco rastros en los archivos estatales.

En fin, todo esto era un descubrimiento muy grande, y obligaba a sentarnos a pensar las maneras de abordarlo, no solo para un equipo, yo diría para varias generaciones. Teníamos la intensidad del descubrimiento, pero todavía estábamos bastante crudos con relación a cómo abordar esos archivos. No porque hubiera prevenciones acerca de lo que es la policía o el servicio penitenciario, que todos sabemos lo que es, esto estaba desde el principio. Pero una vez que hemos decidido que esos materiales son provechosos, ¿qué podemos hacer con ellos? ¿cómo trabajarlos? Y ahí viene la parte donde comienza a bajarse en escalas, y a refinarse y a pensarse más allá de la sospecha que, por supuesto, todos traemos cuando ingresamos en estos archivos. ¿Qué otra herramienta podemos poner a trabajar? Y esa sospecha también había que interrogarla, a veces era útil pero a veces bloqueaba cosas que podrían ser provechosas. No todo lo que traíamos en ese sentido era historiográficamente rendidor. La cuestión principal para mí era ¿cómo usar estos materiales? ¿cómo podíamos ponerlos a trabajar para la historia? Y sigue siendo la gran pregunta.

Entrevistadoras: ¿cuáles fueron las estrategias y decisiones metodológicas que guiaron sus trabajos allí? ¿De qué manera esos archivos desafiaron sus investigaciones? ¿Les llevaron a repensar las formas de lectura o a generar una metodología específica?

Sofía Tiscornia: No he trabajado con un solo archivo, dadas las características del trabajo. El trabajo en archivos ha sido parte de investigaciones etnográficas. Por ello no es sencillo explicar las estrategias y decisiones metodológicas.

Creo que he tenido dos tipos de llegada y, por lo tanto, de estrategias no siempre planeadas con los archivos. Una, ha sido llegar al archivo guiada por alguien experto, quiero decir, en tanto el trabajo con los archivos judiciales, ha sido provocado por comprender cómo habían sucedido o sucedían determinados hechos concretos -detenciones sin orden judicial, enfrentamientos policiales fraguados, razzias, y así- necesité entender la jerga, las fórmulas, los pasos de los procesos, aprender derecho diría y aprender cómo se hacía en diferentes momentos -según qué código de procedimientos regia- y según quiénes eran los actores involucrados. La lectura de expedientes, de series de documentos policiales, de jurisprudencia o de causas judiciales y administrativas, es un trabajo tedioso, pero en la medida que es conversado, discutido, es también un aprendizaje y ahí está el encanto. En comprender, en descubrir.

Muchas veces el archivo consultado me ha permitido comprender las rutinas más acostumbradas de la burocracia que en ellos ha inscripto el trabajo diario y también los pequeños desvíos, las estrategias que quedan ocultas, las pequeñas venganzas del burócrata, el uso a veces estratégico de las fórmulas cortesanas, todo ese mundo menudo y, otra vez, tan vivo. Y que es el que nos encanta a les antropologues que en los pequeños detalles creemos comprender el mundo. Recuerdo, por ejemplo, cómo en la minuciosa lectura del archivo de un caso judicial, unas meras iniciales en una notificación permitieron aclarar quién había hecho un dictamen y se estaba ocultando porque su prestigio no podía exponerse en lo que estaba dictaminando. O las pequeñas guerras internas en las que no se usa la fórmula de prestigio al terminar el escrito porque se considera que no lo merece, aún exponiéndose al rechazo del escrito. Cientos de miles de nimias disputas que solo se descubren en esa lectura tenaz que devela los enconos, las burlas, las jerarquías impugnadas. Y también los errores que el trabajo mecánico y desaprensivo provoca y que da pistas también sobre la indolencia de los tribunales.

Y sí, me llevaron a repensar formas de lectura. Por ejemplo, a entender cómo pasa el lenguaje judicial al lenguaje periodístico, según que se está publicitando, dando a conocer y según las diferentes épocas y retóricas y también el interés en el caso. Como leer desde un lado o del otro e incluso las transformaciones literarias. Más aún cuando las policías suelen -o solían - ser buenos en el arte de presentar sus casos de forma de que sean periodísticamente convincentes y atractivos, y así obtener publicidad y fama. Así fue, por ejemplo, en los casos policiales fraguados, y también fue esa ficcionalización particular que los policías cultivaban lo que permitió, 
en la revisión que se hiciera en las hemerotecas, identificar varios casos que luego fueron investigados por los tribunales. Seguir esos indicios y luego contrastarlos con casos que ya estaban en proceso.

La otra estrategia, porque sería demasiado llamarla metodología, ha sido cierta forma de vagar, de deambular por las pistas que algunos datos de los archivos parecían dar. Actualmente con la web, uno posiblemente recorre muchos más caminos, pero me refiero a una época no muy lejana en que la web nos daba pocos datos, a veces pistas, sí. Pero, en cambio, podíamos perdernos en librerías de viejo y en sus sótanos, de la Avenida de Mayo o del barrio de Tribunales, en expedientes conexos que nos facilitaba algún amigo erudito, en libros de jurisprudencia, en diccionarios de latín jurídico que nos llevaba a ideas insospechadas para la comprensión de los que queríamos explicar. Y aquí también, diría que ese deambular ha sido en buena medida el trabajo de campo, estar dentro del juzgado, la oficina de cancillería, el cuartito de la ONG, que nos facilitaba las montaña de expedientes para revisar y sistematizar, poder hablar con los actores que hacían día a día los caminos burocráticos y que nos explicaban -al tiempo que discutíamos- los significados de nuestras búsquedas.

Y también la literatura. La literatura policial y la literatura en general. Los archivos me han llevado a la lectura tanto de autores de época, como de contemporáneos que muchas veces narran de forma exquisita buena parte de las cuestiones que nos interesan. Ficcionalizadas, sí. Pero son diferentes formas de construcción de los hechos. Y todas iluminan.

Lila Caimari: Ahora está tan de moda hablar del archivo, una se encuentra con reflexiones sobre los archivos por todas partes. Pero realmente creo que hay algo del vínculo con los archivos policiales y con la potencia de este hallazgo que marcó nuestro camino de reflexión sobre los archivos en general. Eran archivos de enorme diversidad, y podían ser la base de caminos y abordajes muy distintos. Y parte de ese camino fue un ejercicio de aprendizaje de tomar las riendas de esos materiales, de aprender a utilizarlos para la historia. Las maneras dependían mucho de las zonas: zonas de memorias, zonas criminológicas, zonas vinculadas con las revistas de la familia policial. Eran materiales muy distintos entre sí y se prestaban a usos muy variados. En líneas generales, lo que aprendimos a hacer, aunque parezca una perogrullada, es a reconstruir las condiciones de producción. Estar ahí sentados en las oficinas donde se producían archivos similares también nos llamó la atención sobre ciertas preguntas: ¿de dónde venía esto?, ¿quién lo producía?, ¿con qué objeto? En fin, las preguntas básicas que ahora cualquier estudiante que entra por primera vez sabe que tiene que hacer.

Otro elemento con consecuencias fue la comprobación de que no se trataba de archivos estáticos. Íbamos a buscar al archivo información sobre tal o cual cosa. Y parte de nuestro aprendizaje tuvo que ver con entender que estábamos trabajando con materiales que formaban parte de un mapa de circulaciones y que éstas revelaban la articulación entre la policía y otras instituciones del Estado. Y con eso, la enorme diversidad de la institución misma. Porque claramente la diversidad del archivo era el reflejo de la institución y sus inscripciones sociales, institucionales, políticas, culturales incluso. Entonces, una parte de lo que fuimos aprendiendo a hacer era a reconstruir esos circuitos, esos mapas y esas articulaciones. Cada uno de esos caminos tenía que ver con intereses singulares de cada uno, y con estas cartografías que se iban armando, siguiendo los documentos mismos una vez que estábamos más familiarizados. Porque también hay un tiempo indispensable de conocimiento, mil detalles que son difíciles de adquirir rápidamente.

Otro hallazgo es que había corpus de materiales sorprendentemente porosos, más inespecíficos de lo previsto: revistas policiales que se parecían a revistas no policiales, por ejemplo. Es decir: estaba lo muy específico de un tipo de burocracia estatal, de un tipo de discurso profesional y profesionalizador, y también había mucho material que hablaba de los tipos de vínculos posibles entre la policía y grupos sociales. Sobre todo en los corpus hemerográficos, en las revistas, que llevaban por caminos totalmente distintos, vinculados a discursos dirigidos no tanto hacia adentro o a un público científico sino a un público más inespecífico de lectores de una familia policial ampliada. Entonces la cuestión también era ¿para quién está escrito esto? La memoria está escrita para que la lea el ministro con una cantidad de expectativas ligadas a demostrar que se hicieron bien las cosas, y que si no se hicieron bien fue por falta de presupuesto. Había cierto tipo de 
premisas implícitas a los distintos géneros al interior de ese archivo. La memoria policial es un género no tan distinto a las memorias de otras agencias estatales. Por completo distinta al género revista policial, que aprendimos también a trabajar. En fin, hubo aprendizajes metodológicos y de abordajes que se vinculaban a las especificidades del corpus que cada uno eligiera.

En todos los casos, fue importante pensar de qué manera estas piezas se conectaban entre sí, y también con archivos que estaban afuera de la policía, ya fuese dentro o fuera del Estado. Pronto entendimos que cada uno de estos corpus requerían de tratamientos diferentes [...] Además de tener a Mariana Nazar en el equipo, quien nos educó en muchas nociones básicas de conciencia documental, tuvimos un curso acelerado de aprendizaje en el territorio. Si todo hubiera estado ordenado en un archivito prolijo y más separado de la institución, quizás algo de esa experiencia se hubiera perdido.

Entrevistadoras: ¿Cuáles fueron las condiciones de acceso a los respectivos archivos donde realizaron sus exploraciones? ¿los archivos que consultaron tuvieron particularidades en lo que respecta a la accesibilidad?

Sofía Tiscornia: Como he dicho ya, en mi caso en general he llegado al archivo de la mano de quien me enseñaba a su vez el camino en el laberinto, eso facilita muchas cosas y, en todo caso, luego solo resta el trabajo de búsqueda concreta y aquí me refiero, en particular, a los archivos de causas judiciales, de expedientes que dormían en el Palacio de Tribunales y que, hasta diría, ni siquiera eran aún series documentales catalogadas, sino archivos vivos que estaban en desuso en estanterías llenas de polvo y olvido.

Diferente ha sido, en cambio, cuando he querido hacer consultas en el archivo histórico de la Policía Federal. Me he sentido muy identificada con el artículo en el libro de Lila (Caimari, 2017), aunque a diferencia de ella, no continué la búsqueda y di por perdida la información que buscaba.

También están las propias series que una va armando, recopilando el material que las burocracias producen y desechan. Por ejemplo, hace unos cuantos años descubrimos que la Policía Federal imprimía todos los días las órdenes del día y esta, además de llegar a las comisarías y otras dependencias policiales, eran giradas a juzgados, a personal jerárquico de determinadas oficinas públicas y claro, inmediatamente desechadas porque su vigencia era diaria. Así que los buenos contactos del trabajo de campo hicieron que nos juntáramos con una serie importante de ellas, que nos remitían todos los días - casi diría que, con cierta sorna, de la especie, "a ustedes les interesa cada cosa..." - y armamos una buena serie que nos permitió comprender mucho mejor el funcionamiento de la policía en la calle, la forma de organizar cierta propaganda, los lazos con las órdenes políticas, y así. Parte de ello lo he relatado en el trabajo sobre el caso de Walter Bulacio (Tiscornia, 2008). Para esa investigación, comprender esas órdenes, fue clave.

Lila Caimari: Creo que, como lo llaman los cronistas, el in situ fue fundamental en el proceso de aprendizaje. Que se entienda bien, ojalá tuviéramos todo digitalizado, se pudiera acceder, no hubiera que pasar por toda clase de humillaciones, de pedidos de favores y de excepcionalidades, eso me lo hubiera evitado con todo gusto y no quiero romantizar un camino que estuvo también lleno de ribetes desagradables. Por otro lado, es muy cierto que la propia colocación de los archivos, y diría más, estar trabajando sobre ciertos archivos pero tener alrededor de uno esta especie de contigüidad de tantas producciones distintas de la policía, produjo un efecto de conjunto que estaba dado por el clima que se respiraba en ese lugar. Incluso por el camino que hubo que transitar para llegar ahí, por el diálogo con quienes estaban cuidándolo, fuese mejor o fuese peor. Creo que aprendimos, sobre todo, en la comprobación de las contigüidades. Si se aterriza directamente sobre la foto digital que se está buscando, sin pasar por todo eso, se pierde todo ese camino, que puede ser tan instructivo. Eso es cierto para el archivo policial pero también para muchos otros. Se trata de una cuestión fundamental ligada a la digitalización del archivo. La intensidad de la experiencia del archivo se debilita enormemente si no hay alguna forma de contacto físico con los materiales. Yo no diría con todos los materiales, pero sí del corpus núcleo del trabajo. No me gusta cultivar una idea romántica del archivo de papel, en el que también había muchas limitaciones. Quisiera imaginar trayectorias que permitan combinar las dos cosas: la democratización del acceso que promete la digitalización con la densidad de la experiencia del in situ 
en el archivo. Y todo lo que uno aprende sin darse cuenta. Tuve dos tipos de producto de esa experiencia. Uno era para CONICET. Yo venía con un proyecto, para cumplir con ese proyecto me acerqué a este archivo y trabajé tales corpus y escribí artículos y libros. Y después esa experiencia me generó una vertiente de escritura paralela, mucho más heterogénea en sus géneros, en sus inscripciones, mucho más incluso despegada de las reglas que si hubiera trabajado con un corpus digital, si hubiera podido acceder haciendo clic en mi máquina y ya. Y esto incluye toda la reflexión sobre el archivo mismo, que no es solo mía, que fue una reflexión colectiva, construida a lo largo de años de hablar sobre estas cosas con todo el equipo. Pero en todo caso, hay ese plus de la reflexión, como una secreción, una reflexión no prevista, que provino de la experiencia personal de la investigación. Y creo es una pérdida grande si uno lo elimina de la investigación, como proyecto personal y como apuesta colectiva de un equipo.

Sé que no hubiera escrito ese librito sobre la vida en los archivos de no haber pasado por esa experiencia (Caimari, 2017). Pero ahí también está la huella del paso por otros archivos, porque la experiencia del archivo es intensa en general. Tiene un plus que sin duda no existe en el trabajo con el archivo digital. Y en este caso, estaba el plus adicional de que los archivos estaban encapsulados en las mismas instituciones. Había que ir a la policía, o al Servicio Penitenciario. Pero al resaltar ese plus no quiero hacer como los policías que dicen "yo la viví", "a mí me vas a venir a explicar", porque había mucho de eso que no estaba bien, todos considerábamos que el archivo debía estar en otra parte. Que el archivo se haya mudado fuera de la comisaría donde estaba y que ahora esté en otro lugar que sigue estando dentro de la esfera de la policía pero se supone está destinado a investigadores, ese desplazamiento indica que ha habido un aprendizaje dentro de la policía, porque en la policía también ha habido movimiento, una toma de conciencia en relación al valor que pueden tener esos papeles para investigadores del mundo de afuera, cuya presencia no sea percibida como pura amenaza o estorbo. Hay signos de que algo hemos avanzado. Pienso en el proyecto actual de hacer un archivo del Ministerio de Seguridad como el fruto de las experiencias que tuvimos los miembros de toda una generación, como Sofía Tiscornia y Sabina Frederic. Hay muchísimas cosas creativas que se siguen pudiendo hacer con el archivo, y lo que ustedes hagan será distinto a los que hicimos nosotros. Y diría, por suerte.

[...] El descubrimiento de estos archivos me demoró mucho más de lo que esperaba en esta exploración. Yo había ido con una noción más bien instrumental, a buscar datos sobre cierta cosa, venía de una investigación sobre la prisión, y no pensaba ponerme a trabajar sobre la policía y la ciudad.Terminé haciéndolo llevada por ese mismo interés casi irresistible que me suscitó el archivo [...] Y el archivo me enseñó lo que uno siempre aprende: que las cosas no siempre son lo que parecen. Que las cosas suelen ser muy distintas a como uno las imagina. Acercándose al objeto, el objeto siempre va a sorprender. Y está en la habilidad de quien investiga permitir que esas sorpresas modifiquen sus ideas previas, y a la vez evitar ser tomado por el archivo. Porque hay un peligro en estos archivos tan intensos y fascinantes, que es que tomen por asalto nuestras investigaciones. Entonces, por un lado, hay que dejarse llevar y ser sensibles a las posibilidades que abren, y a la vez no perder las riendas de las preguntas que uno quiere hacer y las que no quiere hacer, lo que se hace cargo uno y lo que uno delega en otros. Salí muy transformada de esa experiencia. Hace años que no escribo sobre los asuntos que investigaba en esos años, y curiosamente, sigo conectada a aquello por la vía del archivo, no tanto por la policía.

Segunda PARTE: LuCES Y SOMbras Del ACCESo A LOS ARChivos EN TIEMPo De HUMANIDADES DIGITALES

Entrevistadoras: nos quedamos pensando algo de las humanidades digitales, creo que hay un punto en el que estar con los pies en el barro, en la molestia de habitar un espacio tan hostil por momentos, que genera necesariamente una reflexión para poder encarar determinados materiales. Me parece a mí que al estar a un clic de determinados documentos, que al no estar esa molestia, se cae muy fácilmente 
en la tentación por la información literal que contiene el documento sin problematizar todo el resto porque como se está yendo a buscar eso, se lo toma y se lo mete en la investigación sin más.

Lila Caimari: Es cierto eso que decís y es lo que dice Lara Putnam (2016) en su texto sobre el peligro que proviene del adelgazamiento experiencial que trae el archivo digital puro y, sobre todo, el borramiento de los contextos de sentido, de la pregunta por los orígenes de producción, todo lo que salteamos al llegar a través de la búsqueda por palabra, que te permite saltear completamente las capas de contexto de producción que preceden a esa figurita que encontraste. Corremos el riesgo de trabajar con archivos de figuritas que pueden ser jugosas respecto de los datos que proveen pero que no podemos analizar acabadamente porque no hicimos ese camino de llegada. Ese camino importa efectivamente, pero de la misma manera que importa cuando trabajamos diarios como objeto: por supuesto que no es lo mismo aterrizar en el artículo que tiene la palabra que buscabas que trabajar con la página del diario y ver qué hay a cada costado de ese artículo, en qué página está, qué publicidades, qué lugar relativo ocupa ese artículo en relación a todo lo demás. Sin hablar de que los contemporáneos, productores y consumidores, leían en papel y no en digital, por lo tanto, estás trasladando todo a una ecología documental que es otra que la de los contemporáneos. Una parte de estos problemas es intrínseca a la digitalización del archivo de la historia en general. ¿Cuánto ganamos y cuánto perdemos en ese pasaje? No soy apocalíptica ni integrada, creo que podemos ganar muchísimo y también perder en ese pasaje. Y eso sí me parece una reflexión para cultivar hoy, y que no teníamos en aquel momento, cuando no había ningún horizonte de digitalización que se planteara. Hoy está eso, y por suerte, porque significa que algunas cosas serán accesibles a más gente, sin tantas disculpas, sin tantas explicaciones, sin tantos compromisos, sin esos caminos que te van contaminando también. Y no extraño nada de eso. Pero bueno, el punto de llegada tiene una intensidad diferencial que no tiene el archivo bajado de una base de datos. Pero eso también es cierto de cualquier hemeroteca. Me hacés hablar de una hemeroteca cualquiera, y te diría algo no tan distinto.

Entrevistadoras: Incluso mientras hablabas pensábamos en algo que venís mencionando hace tiempo sobre tu preocupación sobre las publicaciones periódicas y las mayores posibilidades de digitalización, por ejemplo, en Brasil que en Argentina y cómo eso genera una especie de distorsión de la realidad epocal.

Lila Caimari: Ese es otro tema que también podemos llevar al campo de los archivos que es: ¿qué políticas se van a llevar adelante? ¿cuáles van a ser los corpus que se van a poner en acceso? ¿quién va a decidir eso? Porque no es solamente cuidado con el adelgazamiento del corpus sino qué mapa te va a proveer esta nueva selección, que es una selección mucho más determinante porque la distancia entre el acceso y el no acceso es mucho mayor. Y eso va haciendo nuevos mapas de los archivos posibles. Yo estoy preocupada con eso porque en sociedades precariamente archivizadas como la nuestra, frágilmente o poco archivizadas, lo que termina pasando es el predominio por escándalo de los corpus que están digitalizados, por sobre aquellos que no lo están. Y ese nuevo contraste entre lo visible y lo invisible te dibuja mapas que en mi experiencia pueden volverse tremendamente distorsivos. Por eso aludo al problema en un texto que publiqué hace unos meses (Caimari, 2020).

La Biblioteca Nacional de Brasil digitalizó el corpus principal de diarios en la época de Lula, y no hubo ninguna otra biblioteca sudamericana que hiciera un trabajo similar. Hoy ya se ven los sesgos historiográficos e interpretativos de esa diferencia: todos los libros producidos en el hemisferio norte sobre prensa latinoamericana son sobre Brasil y se ha instalado la idea de que Brasil era el polo dominante de producción y consumo de diarios en la región. ¿Por qué? En buena medida, porque es lo que se ha vuelto accesible. Y mientras tanto, aquí no se pueden digitalizar los diarios, porque lleva tiempo, trabajo y toda clase de recursos; entonces se digitalizan revistas. Muchos grupos de investigación que tienen subsidios digitalizan las revistas que trabajan, porque digitalizar revistas es mucho más barato y no necesitas una política de Estado para hacerlo. Entonces, ¿qué es lo que pasa? Los trabajos sobre el pasado van hacia las revistas. Por ejemplo, la Biblioteca Nacional de España digitalizó Caras y Caretas hace unos años. Entonces, no hay trabajo de historia social de principios de siglo XX que no cite Caras y Caretas, porque eso es fácil de acceder, porque llegas por búsqueda de palabras, etc. 
Menos mal que está digitalizado, por supuesto, ha sido un aporte mayúsculo. Pero si no lo balanceamos con un acceso al corpus que era el más frecuentado por la mayoría de los contemporáneos nos estamos haciendo una idea equivocada del mapa de consumos culturales en Argentina. Luces y sombras, lo que se ve y lo que no se ve, lo que se puede acceder y lo que no. Terminamos un poco siguiendo el ritmo de las decisiones que se toman en la Biblioteca Nacional de España, que tiene repercusiones interpretativas en la historiografía argentina. Es una decisión (muy loable) de la burocracia bibliotecológica española. Pero eso no reemplaza, creo yo, una política de digitalización nacional, que sea de largo plazo y que arme un mapa en donde la cuestión de la representatividad relativa de las piezas sea una consideración. Y que ese mapa digital de la cultura argentina no se guíe solamente por lo que a mí me gusta, lo que publicaron mis amigos, o lo que es fácil poner en línea, una política subdesarrollada, una política de los pobres, la digitalización de los pobres.

Entrevistadoras: hay algo en este adelgazamiento de la experiencia al que te llevan las humanidades digitales o estos procesos de digitalización que terminan armando mapas distorsivos, que más allá de exigir políticas públicas que contemplen buenos procesos de digitalización acordes a proyectos de desarrollo internacional, quizás empezar a insistir en la reflexión metodológica de les investigadores en relación con ese adelgazamiento de la experiencia para reponer qué nos está faltando.

Lila Caimari: ¿Qué ganamos y qué perdemos? Ser conscientes de eso, ni más ni menos. Es tan enorme lo que está pasando en este plano, y tiene tal cantidad de rebotes y es tan transversal, que lo que se diga depende mucho de los usos situados de estas nuevas posibilidades Más allá de las cuestiones metodológicas, que venimos identificando desde hace tiempo, me preocupa en este momento la cuestión de la construcción del corpus digital argentino, cómo queremos que se arme ese mapa, quiénes deberían ser los actores involucrados. ¿Queremos dejar esto en manos de bibliotecas remotas?, ¿̨n manos de grupos PICT?, ¿o consideramos que es una cuestión que deben tomar las instituciones mismas?

Entrevistadoras: hay un tema que cruza todos los artículos del dossier en torno a cómo en los archivos de organismos de inteligencias ya sean policiales o no policiales, se cruzan las valoraciones morales sobre las cuestiones meramente delictuales que se suponía que tenían que informar. ¿Cómo en los archivos se puede ver la inscripción social de la que participaban los agentes de inteligencia?

Lila Caimari: Algo de eso había reflexionado en torno al trabajo sobre las historias criminológicas, donde tenías a los miembros de los equipos de criminólogos y de asistentes de un lado y a los penados del otro, tratando de pensar las premisas que estaban detrás de esos interrogatorios y las maneras en que las respuestas eran evaluadas. Muchas veces las claves no eran científicas, sino morales o de clase. La evidencia era clara en relación con la inmersión de estas instituciones en el mundo de valores más amplios que brindaban las claves de los modos de procesar la información. Lo que pasa es que es difícil formular un principio, van apareciendo huellas de eso. Y lo que hay que hacer es reunirlas y tratar de producir una reflexión al respecto. Pero necesitas la prueba y la prueba está en los archivos. No están en un vacío moral estas instituciones, están en el mundo, el mundo de su tiempo. Entonces uno está jugando entre la especificidad y la conexión: la formación específica de los tipos, y las agendas políticas o científicas; y los valores más generales de la sociedad en la que están insertos.

[...] Qué adjetivos se usan es importante. Qué adjetivos hay disponibles para describir en el formulario. Y cómo se usan estos formularios, si se usan o no. Lecturas densas de los documentos... ¿eso remite a qué? Son síntomas que te da el documento. Pero tampoco hay que sobreinterpretarlo, algo que ocurre a veces porque es lo que tenemos. Hay que hacer las paces con el hecho de que hay cosas que no vamos a poder saber. Los documentos nos pueden decir cosas, hay dimensiones que podemos plantear como hipótesis, como posibilidad, pero no vamos a poder zanjarlas taxativamente. Los documentos son lo que son, y es mejor evitar lecturas forzadas o voluntaristas, por más trabajo de contextualización que hagamos para subsanar esos límites. Si no funciona, no funciona. Es importante que ese límite sea claro y creo que mientras más explícitamente se reconozca es mejor. Porque no hay magia, por más virtuosismo de investigación que se 
despliegue. Y también me parece enriquecedor traer a la narrativa estas vacilaciones, participar al lector o lectora de estos dilemas.

\section{Entrevistadoras: y tampoco hay archivos mágicos...}

Lila Caimari: Así es. Por eso importa construir una voz propia en relación con todo eso. El archivo te da lo que te da, pero es una la que tiene que construir esa traducción del archivo a preguntas y problemas. Y eso se da en la construcción de una voz propia, y cada uno hace su camino. No hay muchas fórmulas.

\section{REFERENCIAS}

Balbuena, Y. (2019). Simone de Beauvoir: la mala educadora. Una indagación histórica sobre el problema de la invisibilidad (1954-1970) (Trabajo final de la Especialización en Educación en Géneros y Sexualidades). Universidad Nacional de La Plata. Ensenada. Argentina. Recuperada de: http://www.memoria.fahce.unlp.edu .ar/tesis/te.1880/te.1880.pdf

Caimari, L. (2017). La vida en el archivo. Goces, tedios y desvios en el oficio de la historia. Buenos Aires: Siglo XXI Editores.

Caimari, L. (2020). El Momento Archivos. Población \& Sociedad, 27(2), 222-233. Recuperado de: https://doi.org/1 $0.19137 /$ pys-2020-270210

Putman, L. (2016). The Transnational and the Text-Searchable: Digitized Sources and the Shadows They Cast. The American Historical Review, 121(2), 377-402. Recuperado de: https://doi.org/10.1093/ahr/121.2.377

Tiscornia, S. (2004). Entre el honor y los parientes. Los edictos policiales y los fallos de la Corte Suprema de Justicia. El caso de "las Damas de la calle Florida" (1948-1957). En S. Tiscornia (comp.), Burocracias y violencia. Estudios de antropologia jurídica (pp. 13-62). Buenos Aires: Antropofagia.

Tiscornia, S. (2008). Activismo de los derechos humanos y burocracias estatales. El caso Walter Bulacio. Buenos Aires: Editores del Puerto.

\section{Notas}

1 El grupo de investigación sobre delito y castigo en perspectiva histórica Crimen y Sociedad nació en la Universidad de San Andrés en el año 2004. Respondiendo al creciente interés que en los últimos años había concitado ese campo de estudios, dos profesores con interés en el desarrollo del área, Lila Caimari y Eduardo Zimmermann, solicitaron entonces ayuda financiera para constituir un grupo formal de investigación. Desde 2007, gracias a un subsidio PICT de la Agencia Nacional de Promoción Científica y Tecnológica, el grupo está consolidado formalmente. https://repositorio.udesa.e du.ar/jspui/handle/10908/16016\}

2 Sobre su trayectoria ver el Ciclo Trayectorias del Colegio de Graduados en Antropología - Sofía Tiscornia: https://vi meo.com/user2101895

3 Universidad de Buenos Aires, Facultad de Filosofía y Letras, Instituto de Antropología Social. Véase: https://www.an tropojuridica.com.ar 